\title{
Análise de um curso híbrido preparatório para a Olimpíada Brasileira de Astronomia e Astronáutica
}

\author{
Leandro Donizete Moraes ${ }^{1}$ \\ Ismar Frango Silveira ${ }^{2}$
}

Resumo: Este artigo tem o objetivo de apresentar e analisar um curso preparatório para a Olimpíada Brasileira de Astronomia e Astronáutica, em que participaram doze alunos de uma escola pública de Minas Gerais. As atividades foram realizadas em aulas presenciais e também online. Como recursos foram usados formulários, testes, site do curso, atividades práticas e online, softwares, aplicativos e observações do céu. Como referencial teórico, foram utilizados os Três Momentos Pedagógicos à luz de Delizoicov e Angotti. Dentre os resultados, observou-se que o uso de um site com os conteúdos estudados permitiu aos alunos revisarem os conceitos abordados e aprofundarem seus conhecimentos sobre Astronomia e Astronáutica. Além disso, o software Stellarium e o aplicativo SkyMap apresentaram maneiras diferentes para a observação do céu e notou-se que os alunos mudaram suas concepções sobre fenômenos como as estações do ano. Estes e outros resultados demonstram as potencialidades do uso de recursos tecnológicos como mediadores entre o ensino e a aprendizagem e também realçam a importância da conciliação entre a tecnologia e as atividades tradicionais de ensino de Astronomia, como a observação do céu a olho nu, por exemplo.

Palavras-chave: Educação em Astronomia; Educação não formal; Tecnologias da Informação e Comunicação

\section{Analysis of a hybrid preparatory course for the Brazilian Astronomy and Astronautics Olympics}

Abstract: This article presents and analyses a preparatory course for the Brazilian Olympics of Astronomy and Astronautics offered to twelve participants who were students of a public school in Minas Gerais state. Various presential and virtual resources were used to carry out the activities, such as forms,

\footnotetext{
1 Mestre em Ensino de Física, doutorando em Ensino de Ciências e Matemática pela Universidade Cruzeiro do Sul e professor de educação básica da Secretaria Estadual de Educação de Minas Gerais. E-mail: leandrosta2009@hotmail.com

2 Doutor em Engenharia Elétrica, professor adjunto da Universidade Presbiteriana Mackenzie e professor titular da Universidade Cruzeiro do Sul. E-mail: ismar.silveira@cruzeirodosul.edu.br
} 
tests, a website for the course, practical and online tasks, software, applications, and sky observations. The theoretical review is based on the Three Pedagogical Moments in the light of Delizoicov and Angotti. Among the results, it was observed that the use of a website containing the class contents allowed the students to revise the concepts studied and deepen their knowledge in Astronomy and Astronautics. Moreover, the software Stellarium and the application SkyMap offered different ways to observe the sky. Results show that the students changed their perspectives about phenomena like the seasons of the year. The conclusions of this study demonstrated the potential of using technology resources as mediators between teaching and learning, while highlighting the importance of conciliation between technology and traditional teaching activities of Astronomy, such as naked eye sky observation.

Keywords: Education in Astronomy; Non-formal Education; Information and Communication Technologies

Desde a antiguidade, a observação dos fenômenos celestes desperta a curiosidade humana e a busca por respostas sobre nossa origem e destino. A Astronomia possui o céu como laboratório e permite à humanidade buscar seu lugar no Universo. A Astronáutica, por sua vez, incentiva os seres humanos a sonharem com a conquista de novos mundos e desperta variados desejos, tanto científicos quanto fictícios. Pela importância destas ciências, elas deveriam ocupar um lugar de destaque nos ambientes escolares. Porém, ao analisar a literatura da área de Educação em Astronomia, por exemplo, nota-se que existem vários problemas, desde erros conceituais de alunos e professores até a ausência deste ensino em muitas escolas.

Dentre as pesquisas realizadas sobre Educação em Astronomia, Siemsen e Lorenzetti (2019) observaram que há fragmentação do ensino de Astronomia e pouca potencialidade do desenvolvimento de atividades interdisciplinares que incluam tal conteúdo na Base Nacional Comum Curricular, BNCC; Sobreira (2002) alertou para os erros conceituais encontrados em livros didáticos; Bisch (1998) criticou o "ensino livresco" de muitos professores; Langhi e Nardi (2012) analisaram os problemas enfrentados ao ensinar esta ciência, como as deficiências na formação de professores e as concepções alternativas; Longhini (2010) apresentou experiências e contribuições para o ensino de Astronomia; e, Darroz e Santos (2013) elaboraram uma proposta didática para a formação de professores para o ensino de Astronomia.

A Astronomia pode ser ensinada de várias maneiras por meio da educação formal, não formal e informal. Marandino (2008) explica que não é uma tarefa fácil distinguir estes tipos de educação. Porém, alguns autores buscam significados para cada um deles, como Gohn (2006), por exemplo, ao explicar que a educação formal é aquela ensinada nas escolas com conteúdos demarcados, enquanto Langhi e Nardi (2009) acrescentam que este tipo de educação possui avaliações e cronogramas específicos, além de um conhecimento organizado, sistematizado e estruturado. Sobre a educação não formal, Marques (2017) analisa que este também é um tipo de educação organizado e sistematizado, porém mais flexível 
quanto ao tempo e espaços de aprendizagem. Como exemplos de espaços não formais, destacam-se os observatórios, planetários e ambientes virtuais de aprendizagem. Por fim, Gaspar (2002) explica que na educação informal não há lugar, currículos ou horários para aprender e os conhecimentos são oriundos da interação sociocultural por meio de normas de comportamento, sobrevivência, dentre outros.

Sobre o uso de recursos tecnológicos para o ensino de Astronomia, Ferreira (2014) analisou diversas possibilidades para o ensino de Astronomia em ambientes virtuais, enquanto Ravotto e Bellini (2008) enfatizam que o uso das Tecnologias de Informação e Comunicação (TIC) pode chamar mais atenção dos alunos aos conteúdos discutidos através de aulas interativas. Além disso, Kenski (2007) explica que é um desafio inventar e descobrir maneiras criativas de utilizar a tecnologia educacional para inspirar alunos e professores a gostarem de aprender.

Diante do fato de que a educação não formal permite que as pessoas interessadas em determinados conteúdos possam aprender de maneira mais flexível quanto ao tempo e espaço de aprendizagem, sem a necessidade de frequentar cursos formais, e que o uso de recursos tecnológicos pode auxiliar na aprendizagem, o presente artigo analisa a aplicação de um curso híbrido preparatório para a Olimpíada Brasileira de Astronomia e Astronáutica (OBA) com o uso de recursos tecnológicos. De acordo com Canalle et al. (2005), esta olimpíada tem como objetivo informar, corrigir, atualizar e divulgar conteúdos corretos de Astronomia. Sá (2009) diz que a OBA contextualiza conteúdos através de atividades interessantes e lúdicas, contribuindo para a elevação da qualidade da educação no país.

Em relação às pesquisas sobre cursos preparatórios para a OBA, Felicetti et al. (2017)ba fizeram uma oficina com alunos do ensino fundamental por meio de atividades experimentais, vídeos, imagens e discussões, enquanto Barai et al. (2016) utilizaram a OBA como evento motivador para um curso de aperfeiçoamento de professores e palestras para estudantes universitários.

Ao analisar estes e outros cursos preparatórios para a OBA, observa-se que geralmente os conteúdos são apresentados por meio de aulas expositivas e algumas atividades práticas, como a observação do céu, por exemplo. Porém, poucos recursos tecnológicos são usados como auxílio à aprendizagem. O software Stellarium é o mais utilizado em cursos deste formato e são raras as vezes em que são usados outros recursos, como atividades na Internet. Além disso, os cursos, em geral, não apresentam ambientes virtuais nos quais os materiais estejam disponíveis. Por estes e outros motivos, o curso analisado neste artigo busca proporcionar aos participantes a oportunidade de usarem diversos recursos tecnológicos para revisarem os conteúdos e aprofundarem seus estudos.

\section{Metodologia}

Os alunos de uma escola pública do interior de Minas Gerais foram convidados a participar da Olimpíada Brasileira de Astronomia e Astronáutica. Após a seleção dos alunos interessados, criou-se um grupo no WhatsApp para a interação entre o professor coordenador da OBA na escola e os alunos. Por meio deste 
grupo, foi proposta a criação de um curso preparatório para a OBA, o qual se mostrou importante pelo fato desta olimpíada permitir a busca por conhecimentos astronômicos, desmistificando conceitos e dando a oportunidade aos alunos de compreender as causas de vários fenômenos. Além disso, a OBA permite que os alunos possam aprender conteúdos que não são ensinados na escola, como a Astronáutica.

Foi elaborado um formulário nos Formulários Google com algumas perguntas sobre o interesse dos alunos pela Astronomia e os motivos para participarem da OBA. O formulário foi respondido por 36 alunos, porém nem todos possuíam disponibilidade para frequentar aulas presenciais fora do horário escolar, pois eram do Ensino Médio e muitos trabalhavam. Sendo assim, o curso foi realizado por 12 alunos que tinham disponibilidade para participarem de aulas presenciais e também acesso à Internet para realizar as atividades online, que estavam disponíveis em um site no Google Sites. Os conteúdos do curso ficaram disponíveis neste site para todos os alunos, até mesmo para aqueles que não participaram das aulas.

Para a produção, aplicação e análise do curso, foram usados os Três Momentos Pedagógicos (DELIZOICOV, 1991). Esta dinâmica didático-pedagógica foi usada inicialmente em um projeto de ensino de Ciências na Guiné-Bissau, por Delizoicov (1982) e Angotti (1982). Inspirados pelas teorias de Paulo Freire, utilizaram-se dos denominados temas geradores e, de acordo com Freire (1975), dos processos de codificação-problematização-descodificação para estruturar três momentos pedagógicos que são: problematização inicial, organização do conhecimento e aplicação do conhecimento.

Delizoicov, Angotti e Pernambuco (2002) explicam que a problematização inicial consiste em apresentar aos alunos problemas ou discussões problematizadoras em busca de concepções alternativas que eles possuem. De acordo com os autores, a organização do conhecimento é o momento em que o professor aborda os conceitos científicos através da estruturação do conteúdo e da aprendizagem dos alunos por meio de temas e situações significativas. Por fim, na aplicação do conhecimento os alunos são motivados a empregar os conhecimentos científicos estudados em novas situações, buscando a generalização da conceituação e tornando-se capazes de identificar e empregar a conceituação científica.

O curso híbrido foi dividido em doze aulas presenciais e atividades realizadas no ambiente online do curso, as quais foram distribuídas de acordo com os três momentos pedagógicos. A Tabela 1 apresenta a organização do curso:

Tabela 1 - Organização do curso

\begin{tabular}{lll}
\hline Momentos Pedagógicos & Atividades propostas & Duração (em aulas) \\
\hline \multirow{2}{*}{ Problematização inicial } & Formulário inicial & Online, antes do curso \\
& Pré-teste e discussões & 1 aula \\
\hline
\end{tabular}




\begin{tabular}{|c|c|c|}
\hline Momentos Pedagógicos & Atividades propostas & Duração (em aulas) \\
\hline Organização do conhecimento & $\begin{array}{l}\text { Apresentação do site } \\
\text { Conteúdos da OBA } \\
\text { Astronomia básica } \\
\text { Astronomia moderna }\end{array}$ & $\begin{array}{l}1 \text { aula } \\
1 \text { aula } \\
2 \text { aulas } \\
2 \text { aulas }\end{array}$ \\
\hline Aplicação do conhecimento & $\begin{array}{l}\text { Atividade prática } \\
\text { Sala de informática } \\
\text { Lançamento de foguetes } \\
\text { Observação do céu } \\
\text { Pós-teste e conclusões } \\
\text { Formulário final }\end{array}$ & $\begin{array}{l}1 \text { aula } \\
1 \text { aula } \\
\text { Nas aulas regulares } \\
2 \text { aulas } \\
1 \text { aula } \\
\text { Online, após o curso }\end{array}$ \\
\hline
\end{tabular}

Fonte: elaborado pelos autores

De acordo com a Tabela 1, a problematização inicial teve início através da aplicação de um formulário online realizado antes do curso sobre o interesse dos alunos pela Astronomia e participação da Olimpíada Brasileira de Astronomia e Astronáutica. Na primeira aula foi aplicado um pré-teste com perguntas sobre Astronomia e, em seguida, foram realizadas discussões sobre os conteúdos que seriam estudados nas próximas aulas com o objetivo de identificar concepções alternativas. O segundo momento pedagógico, organização do conhecimento, contou com a apresentação do site através do uso de projetor multimídia, sala de informática, explicação de conteúdos presentes nas provas da OBA e estudos sobre a Astronomia básica e a Astronomia moderna, totalizando seis aulas.

Na aplicação do conhecimento, os alunos fizeram uma atividade prática sobre a comparação entre o tamanho dos planetas e do Sol no sistema solar, atividades na sala de informática, revisão dos conteúdos estudados, lançamento de foguetes na Mostra Brasileira de Foguetes (MOBFOG), observação do céu a olho nu e pelo telescópio com o auxílio de recursos tecnológicos, um pós-teste e discussões sobre o curso. Como instrumentos de coleta e análise de dados foram utilizados formulários online realizados após as aulas, testes presenciais e análise da participação dos alunos nas atividades práticas e no site.

\section{Resultados e discussões}

Para iniciar a problematização, os trinta e seis alunos interessados em participarem da OBA responderam ao formulário online inicial sobre o interesse por esta olimpíada, pela Astronomia e pela Astronáutica. Houve convergências entre as respostas, sendo que 13 alunos (36\%) responderam que gostariam de fazer a OBA porque esta olimpíada daria a oportunidade de aprenderem mais; 7 alunos (19\%) explicaram que iriam fazer a OBA por se interessarem pela Astronomia; 4 alunos (11\%) queriam testar seus conhecimentos; 6 alunos (17\%) acreditam que a OBA possibilita uma maneira diferente de aprender; 4 (11\%) se interessaram pelos prêmios desta olimpíada; e, 2 alunos (6\%) gostariam de fazer 
a OBA por se interessarem por olimpíadas em geral. Na Figura 1 são apresentadas duas das respostas sobre o interesse pela OBA, pela Astronomia e pela Astronáutica.

Figura 1 - Respostas sobre o interesse pela OBA, Astronomia e Astronáutica

A possibilidade de através da olimpíada, conquistar certificados, além de ter a chance de participar de outras olimpíadas (Chile), sempre nutri minha curiosidade por fenômenos astronômicos e, comecei a me interessar realmente pela astronomia a partir de acontecimentos recentes, como a foto de um buraco negro e novidades na questão Marte (água/vida), o que me motivaram a participar da OBA.

Porque a astronomia e astronáutica são uma das das coisas que eu mais amo... e minha meta é exercer uma dessas duas profissões, então fazendo essa prova, talvez meu futuro pode começar ali... e também só de estar fazendo a OBA já é um passo que estarei dando.

Fonte: extraído do formulário inicial

$\mathrm{Na}$ figura 1 observa-se que estes alunos acreditam nas oportunidades oriundas de atividades extracurriculares, como as olimpíadas do conhecimento. Na Figura 2 são apresentadas as respostas dos alunos sobre o que mais gostam em Astronomia.

Figura 2 - O que os alunos mais gostam em Astronomia?

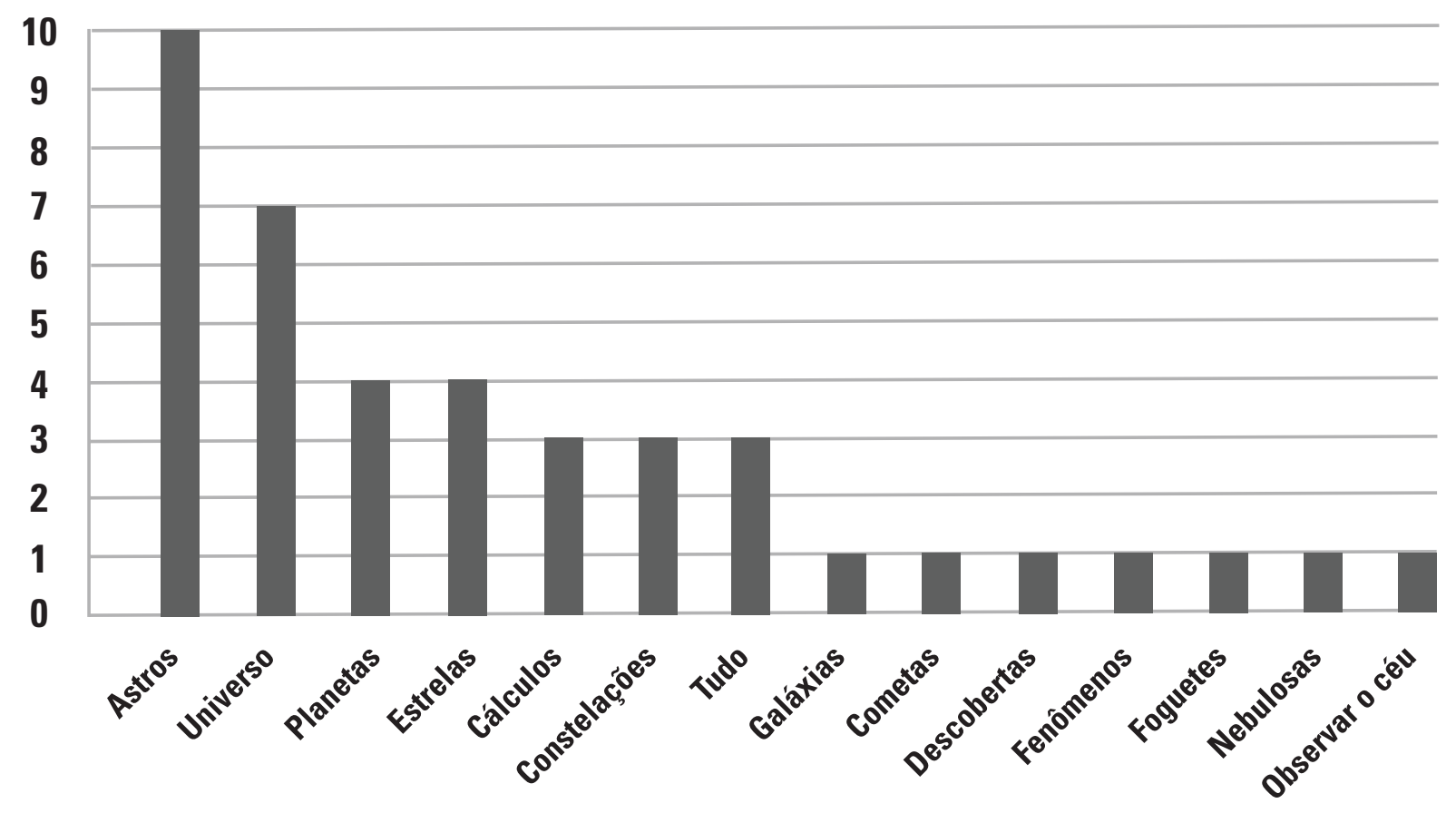

Fonte: extraído do formulário inicial

As respostas para a segunda pergunta demonstram o interesse dos alunos por vários fenômenos e conteúdos de Astronomia. Alguns responderam com mais de um conteúdo ou fenômeno as- 
tronômico. O estudo dos astros, em geral, foi o conteúdo com maior destaque, sendo citado em dez respostas (28\%); o estudo do Universo foi o conteúdo preferido por sete alunos (19\%); planetas e estrelas estiveram presentes em quatro respostas (11\%); o uso de cálculos na Astronomia e o estudo das constelações foram apresentados por três alunos (8\%); o estudo sobre tudo o que é pesquisado pela Astronomia foi preferência de três alunos (8\%); dois alunos (6\%) afirmaram se interessar pelas galáxias e os conteúdos relacionados aos cometas, descobertas científicas, fenômenos astronômicos, foguetes, nebulosas; enquanto observação do céu foi apresentado apenas uma vez (3\%). Estas respostas demonstram que a Astronomia permite a introdução dos alunos ao conhecimento científico através do interesse pelo estudo de conteúdos e fenômenos estudados pela Ciência. Diante disto, Tignanelli (1998) explica que a Astronomia possui caráter interdisciplinar e multidisciplinar, proporcionando o aprendizado não apenas de Astronomia, mas sim de várias ciências.

A terceira pergunta analisou o que os alunos acreditavam que poderia ser feito para o ensino de Astronomia na escola. Dezesseis alunos (44\%) gostariam de aulas de Astronomia na escola; sete alunos (19\%) preferiam aulas práticas de Astronomia; quatro alunos (11\%) queriam observar o céu pelo telescópio; e, três alunos (8\%) pediram aulas de Astronomia fora do horário escolar. As outras propostas foram referidas apenas uma vez: aulas de Física sobre Astronomia, explicação de um modo mais fácil, grupos de estudos, uso de videoaulas, construção de um observatório na escola e pesquisas na sala de informática. Na Figura 3 são apresentas duas das respostas para a terceira pergunta:

Figura 3 - Exemplos de respostas para a terceira pergunta

Poderia ter aula de astronomia uma vez por semana ou até duas, pois tem alunos que gostam de astronomia e não sabe bem por onde começar, para conhecer mais sobre o assunto. Então se tivesse essas aulas por semana iria ajudar muito.

Poderia aulas práticas sobre astronomia.

Fonte: extraído do formulário inicial

As respostas para a terceira pergunta mostram que vários alunos gostariam de estudar Astronomia, porém muitos problemas são encontrados no ensino desta ciência. Dentre eles, Bretones e Compiani (2010) concluíram que a legislação para a formação de professores não especifica quais conteúdos de Astronomia devem ser ensinados, fazendo com que os cursos superiores ofereçam poucas oportunidades para uma formação inicial adequada de professores para o ensino desta ciência. Por outro lado, Leite e Hosoume (2007) observaram a existência de várias concepções errôneas por professores, enquanto Langhi e Nardi (2012) também analisaram concepções alternativas de professores e alunos, mostrando que são necessárias ações para que a formação de professores possibilite novas maneiras de ensinar e aprender. 
Ao analisar as respostas do formulário inicial, observa-se a importância do ensino de Astronomia, pois esta ciência, conforme afirma Caniato (1974), permite uma visão global do desenvolvimento humano, analisa modelos sobre o funcionamento do Universo, oferece atividades ao ar livre e que não necessitam de materiais e laboratórios caros, reflete sobre a percepção da pequenez do homem diante do Universo, dentre várias outras razões.

Na primeira aula foi solicitado aos doze alunos presentes que respondessem a um pré-teste. As perguntas do pré-teste foram elaboradas com o objetivo de identificar concepções alternativas sobre diversos fenômenos e conceitos astronômicos. Dentre as perguntas, foi solicitada a análise das causas das estações do ano, da ocorrência dos eclipses e das fases da Lua. Além disso, os alunos também foram questionados quanto aos conceitos de estrela e planeta e suas diferenças. Na Figura 4 é apresentado o pré-teste e suas perguntas.

Figura 4 - Pré-teste sobre conceitos de Astronomia

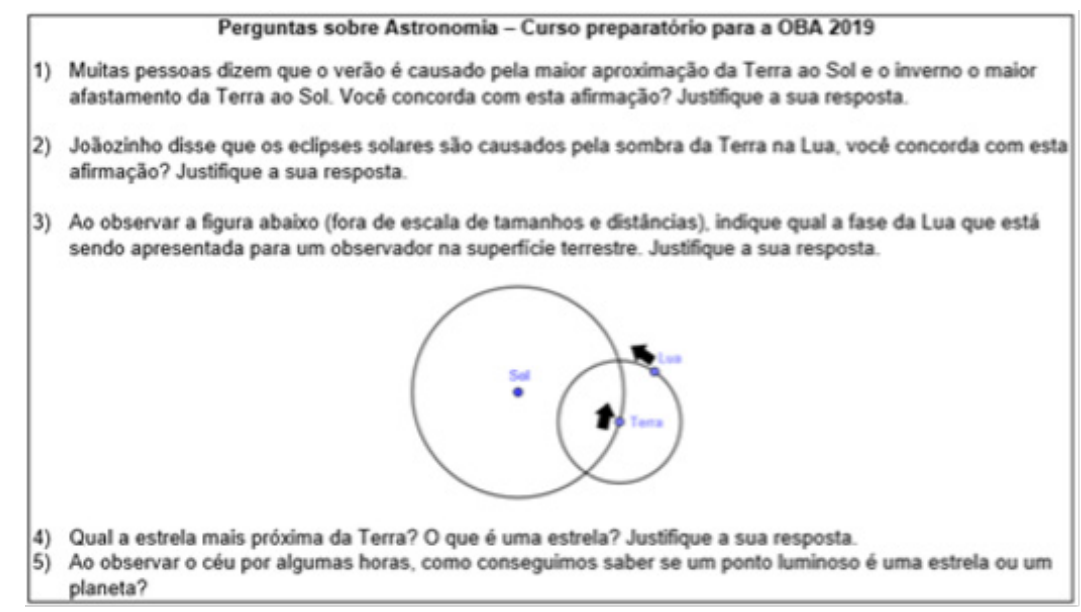

Fonte: extraído do formulário inicial

Em relação à primeira pergunta do pré-teste apresentado na Figura 4, sete alunos (58\%) não concordaram com a afirmação, justificando que as estações do ano ocorrem por causa da inclinação da Terra em seu movimento de translação, enquanto cinco alunos (42\%) concordaram que as estações do ano ocorrem pela distância entre a Terra e o Sol durante o ano. A resposta dos cinco alunos remete à uma concepção alternativa comum sobre as estações do ano. Segundo Camino (1995) até mesmo alguns professores acreditam que as estações do ano ocorrem pela variação da distância entre a Terra e o Sol e que a órbita terrestre no movimento de translação possui grande excentricidade. A resposta apresentada na Figura 5 demonstra esta concepção: 
Figura 5 - Uma das respostas para a primeira pergunta do pré-teste

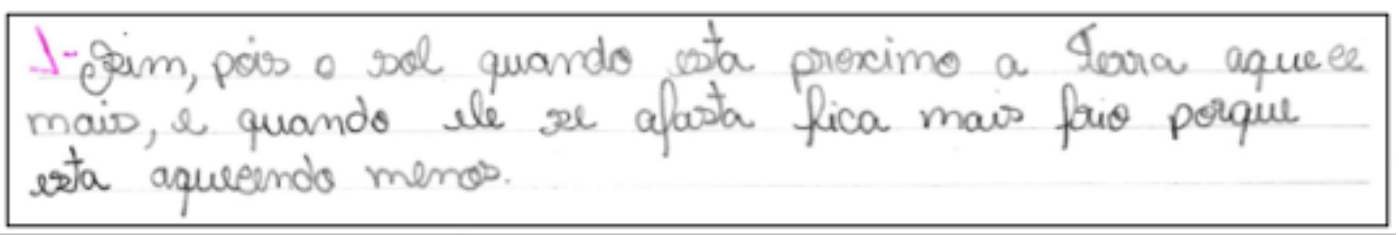

Fonte: extraído do formulário inicial

A segunda pergunta analisou a compreensão dos alunos a respeito das causas dos eclipses. Nove estudantes (75\%) discordaram da afirmação de que os eclipses solares são causados pela sombra da Terra na Lua, e três alunos (25\%) concordaram. Mesmo existindo uma grande porcentagem de alunos que compreenderam este fenômeno, é preciso observar que três responderam de forma incorreta esta pergunta. Na Figura 6 é apresentada uma das respostas incorretas sobre o eclipse solar.

Figura 6 - Uma das respostas para a segunda pergunta do pré-teste

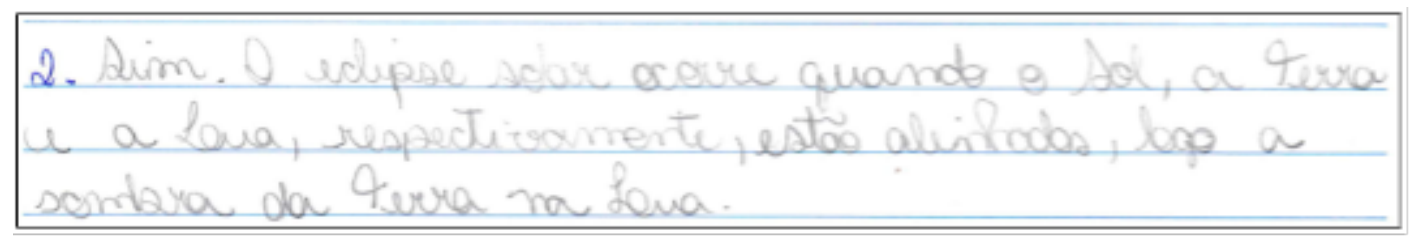

Fonte: extraído do formulário inicial

Para analisar a compreensão sobre as fases da Lua, a terceira pergunta apresenta uma representação, fora de escala, do sistema Sol-Terra-Lua. É observado que a iluminação solar na Lua está diminuindo à medida que a Lua se aproxima do Sol. Por isto, a fase da Lua representada é a fase quarto-minguante. Sete alunos (58\%) responderam corretamente, três (25\%) responderam fase crescente e dois (17\%) fase nova. A Figura 7 apresenta uma das respostas para a terceira pergunta:

Figura 7 - Uma das respostas para a terceira pergunta do pré-teste

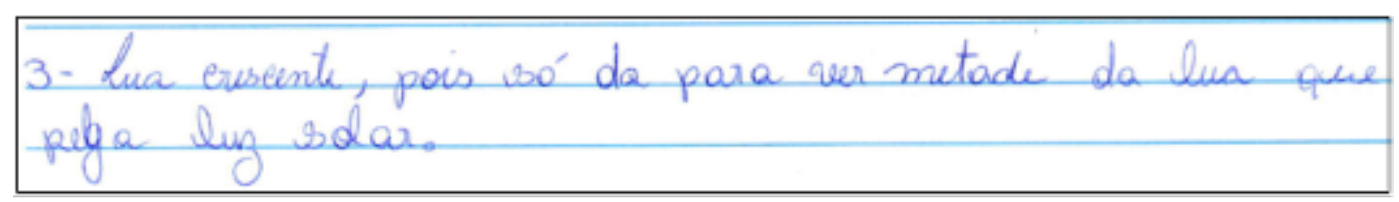

Fonte: extraído do formulário inicial

Ao observar a resposta presente na Figura 7, conclui-se que o aluno não se atentou para o sentido das setas da representação presente na terceira questão, pois a iluminação solar na Lua está diminuindo à medida em que a Lua se aproxima do Sol. Sobre estas concepções, Langhi e Nardi (2007) 
analisaram que muitos livros didáticos apresentam as fases da Lua como consequências dos eclipses e afirmam existir apenas quatro fases lunares. Porém, as fases da Lua se devem à iluminação solar durante o movimento lunar ao redor da Terra enquanto esta gira em torno do Sol. Além disso, não existem apenas quatro fases, pois a parte iluminada da Lua varia a cada instante.

A quarta questão analisou se os alunos sabiam que o Sol é uma estrela, pois é a estrela mais próxima da Terra. Além disso, perguntava sobre o conceito de estrela. Sete alunos (58\%) acertaram a questão, três (25\%) não responderam e dois (17\%) explicaram que Sirius é a estrela mais próxima da Terra.

Sobre a segunda parte da pergunta, houve dificuldades em responder o que é uma estrela. Um aluno (8\%) identificou as estrelas como corpos celestes que sofrem reações entre o hélio e o hidrogênio. Cinco alunos (42\%) disseram que é um conjunto de matéria, três (25\%) não responderam, dois alunos (17\%) afirmaram que são bolas de plasma e um aluno (8\%) explicou que as estrelas são pontos luminosos.

Na última pergunta os alunos deveriam diferenciar estrelas e planetas. Para cinco alunos (42\%), os planetas se movimentam e as estrelas são pontos fixos; três alunos (25\%) não responderam; dois (17\%) disseram que os planetas têm cores diferentes das estrelas; um aluno (8\%) explicou que as estrelas têm maior luminosidade e um aluno (8\%) afirmou que os planetas possuem maior luminosidade.

Em relação aos conceitos de estrelas e planetas, Rodrigues (2007) observou que os conteúdos sobre planetas e sistema solar são tratados com superficialidade e imprecisão nos livros didáticos. Em outro estudo, lachel (2011) analisou o conhecimento prévio dos alunos sobre as estrelas, observando que eles possuem dificuldades em elaborar um modelo explicativo sobre o funcionamento das estrelas, pois alguns alegam que elas possuem pontas e poucos entendem que são formadas por massa de gás.

Após identificar várias concepções alternativas através da aplicação do formulário inicial e do pré-teste, foi iniciada a organização do conhecimento, através de aulas teóricas e práticas sobre conceitos e fenômenos astronômicos. A segunda aula foi realizada na sala de informática, apresentando os conteúdos do site do curso, deixando que os alunos realizassem pesquisas no site para encontrar os conteúdos e atividades.

Como tarefa de casa, os alunos deveriam acessar a página inicial e a sessão intitulada "Introdução do curso" para discutir na próxima aula sobre os conteúdos presentes. Sendo assim, no início da terceira aula os alunos relataram que não conheciam grande parte dos documentários e canais do Youtube indicados na página inicial. Do mesmo modo, não conheciam vídeos e documentários presentes na introdução, assim como a história de vários dos cientistas cujas bibliografias estavam disponíveis. Na sequência da aula, foram apresentados conteúdos da OBA através de questões anteriores desta olimpíada, slides, vídeos, debates e uso do quadro negro. Como tarefa de casa, os alunos deveriam acessar a página "Conteúdos da OBA" e aprofundar seus estudos. 
Ao iniciar a quarta aula, os alunos foram questionados quanto aos estudos sobre a página "Conteúdos da OBA". Em geral, disseram achar que foi importante disponibilizar estes conteúdos na Internet como complemento à terceira aula. Também afirmaram que não conheciam a maioria dos conteúdos apresentados e se interessaram em aprofundarem os estudos sobre Astronomia e Astronáutica.

A quarta e a quinta aula foram destinadas aos conteúdos de Astronomia básica e a sexta e sétima aula sobre Astronomia moderna. Como tarefas de casa, os alunos precisavam acessar e aprofundar os estudos através das páginas "Astronomia básica" e "Astronomia moderna". A Figura 8 apresenta uma das aulas sobre Astronomia moderna, analisando diversos fenômenos, como a formação de galáxias.

Figura 8 - Aula presencial com o uso de recursos tecnológicos

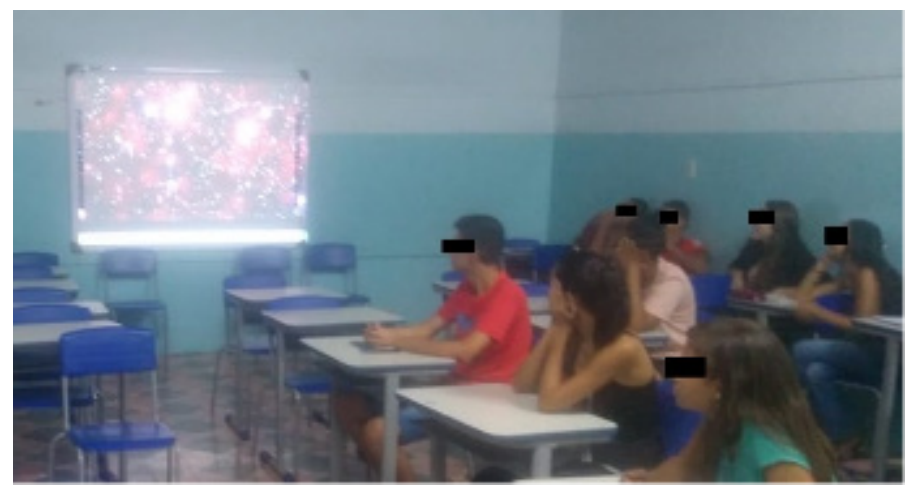

Fonte: extraído do formulário inicial

Em relação às aulas do segundo momento pedagógico, foram analisadas questões da OBA e exibidos vídeos no site sobre Astronáutica, oferecendo estudos para esta área que, muitas vezes, não é ensinada nas escolas. Os alunos acessaram continuamente as páginas do curso, comentando sobre os conteúdos presentes nestas páginas, nos canais do Youtube indicados e nos documentários e filmes. Sendo assim, o uso do site foi importante como complemento às aulas presenciais por permitir aos alunos a revisão e o aprofundamento de estudos, além de apresentar informações e sugestões para que continuassem aprendendo fora das aulas.

Após os dois primeiros momentos pedagógicos, os alunos realizaram atividades para a aplicação do conhecimento, finalizando assim os "Três Momentos Pedagógicos". De início, o terceiro momento pedagógico contou com uma aula prática sobre a relação entre o tamanho dos planetas e o do Sol. A Figura 9 apresenta o sistema solar produzido nesta aula através das proporções dos planetas e do Sol sem a escala de distância entre eles: 
Análise de um curso híbrido preparatório para a

Olimpíada Brasileira de Astronomia e Astronáutica

Figura 9 - Atividade prática: o sistema solar

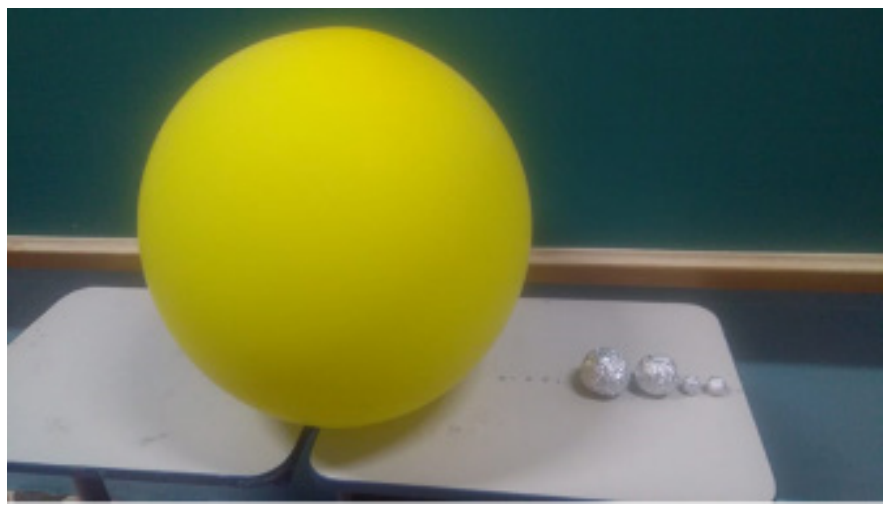

Fonte: extraído do formulário inicial

Esta atividade permitiu a compreensão do sistema solar e a importância do conhecimento sobre a Astronomia básica e moderna, pois já existem evidências da existência de outros sistemas planetários. Também existiram discussões sobre as distâncias espaciais e viagens espaciais. A segunda aula da aplicação do conhecimento contou com atividades na sala de informática da escola. Esta aula permitiu revisões sobre os conteúdos estudados por meio de atividades diversificadas. A Figura 10 mostra os alunos realizando atividades na sala de informática:

Figura 10 - Atividades na sala de informática

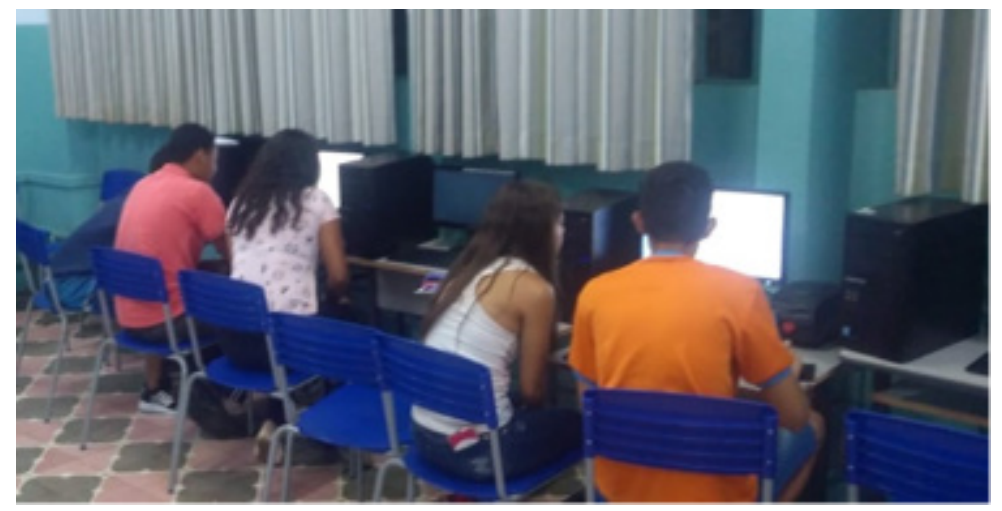

Fonte: extraído do formulário inicial

Dentre as várias atividades realizadas na sala de informática, os alunos acessaram um blog no qual preencheram cruzadinhas sobre conceitos astronômicos e do sistema solar, completaram um texto online sobre as fases da Lua, responderam a um teste relacionado às estações do ano e discutiram os resultados alcançados nestas atividades. Os alunos também lançaram os foguetes de garrafa pet da Mostra Brasileira de Foguetes (MOBFOG). A Figura 11 apresenta um dos lançamentos desta mostra de foguetes. 
Análise de um curso híbrido preparatório para a

Olimpíada Brasileira de Astronomia e Astronáutica

Figura 11 - Lançamento de foguetes da MOBFOG

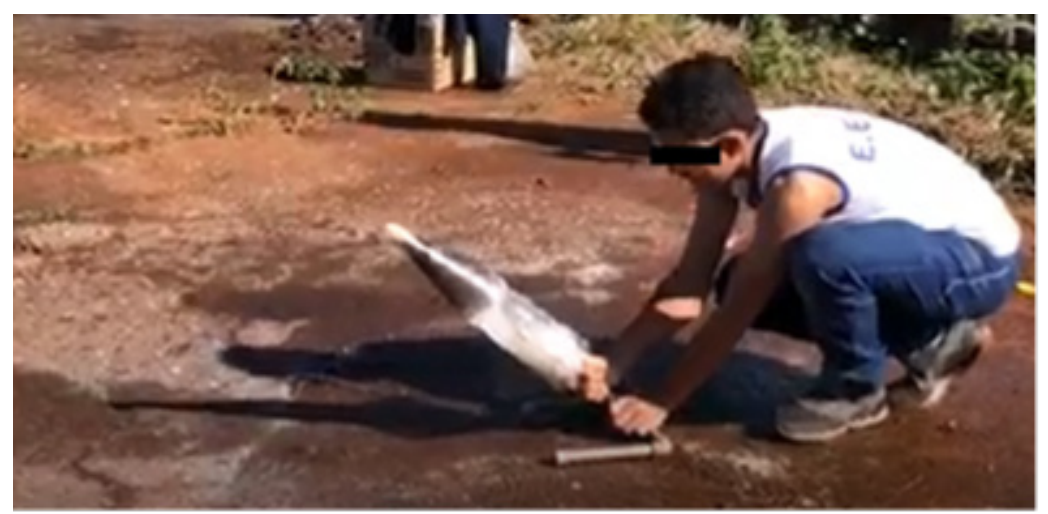

Fonte: extraído do formulário inicial

As duas próximas aulas do curso foram feitas ao ar livre com o uso de um telescópio, do software Stellarium e do aplicativo SkyMap. Os alunos usaram o software Stellarium para várias coordenadas da superfície terrestre, revisando diversos conteúdos. A Figura 12 mostra os alunos observando a projeção do software Stellarium na parede da escola e, ao lado esquerdo, o telescópio que foi utilizado para a observação do céu.

Figura 12 - Observação do céu na escola

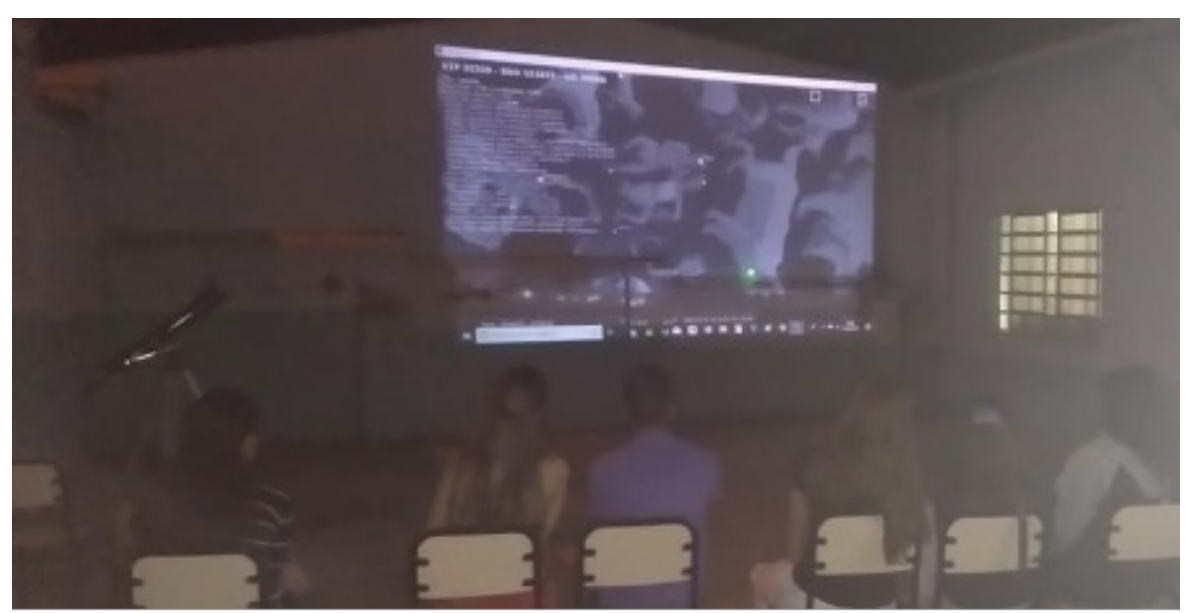

Fonte: extraído do formulário inicial

Além da simulação do céu em diferentes localidades por meio do software Stellarium, os alunos também utilizaram o aplicativo SkyMap para localizar planetas, estrelas e constelações. Durante a observação do céu, foi constatado que o uso destes recursos reforça a importância da tecnologia para o ensino de Astronomia sem deixar de lado atividades tradicionais, como a observação do céu a olho nu e pelo telescópio. 
Para finalizar a aplicação do conhecimento, a última aula contou com a aplicação de um pós-teste que abordou conceitos astronômicos aos quais os alunos apresentaram concepções alternativas no pré-teste, além de outros conceitos que geraram dúvidas durante as aulas. A Figura 13 apresenta o pós-teste:

Figura 13 - Pós-teste

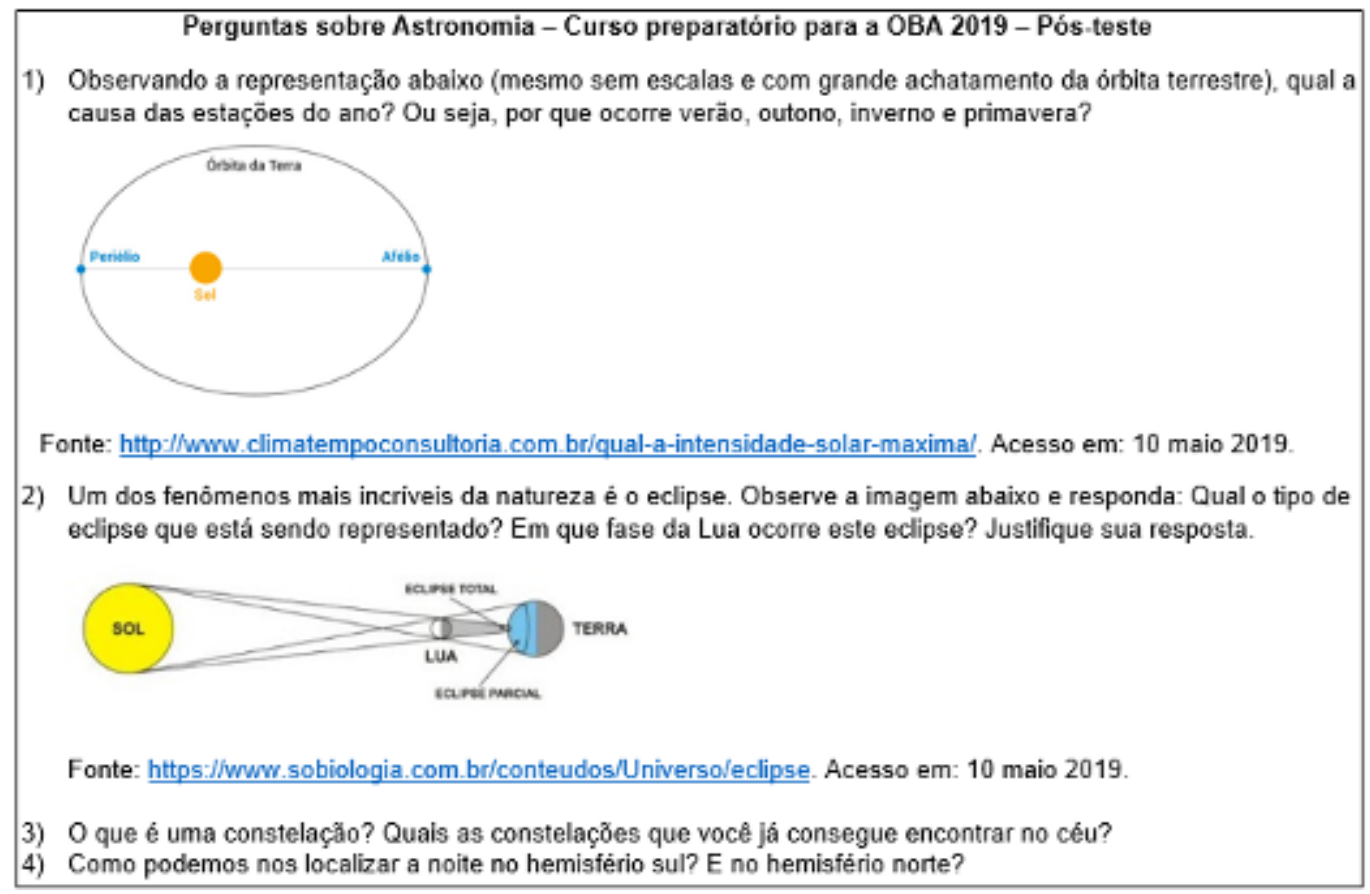

Fonte: extraído do formulário inicial

A primeira pergunta do pós-teste explora o conceito de estações do ano. No pré-teste foi elaborada uma pergunta parecida, porém sem nenhuma figura representando a órbita terrestre. O objetivo de inserir uma figura com grande achatamento da órbita da Terra foi observar se os alunos ainda acreditavam que as estações do ano são causadas pela distância entre a Terra e o Sol durante o ano.

Seis alunos (50\%) responderam que se deve à inclinação terrestre em sua órbita; três (25\%) responderam corretamente que as estações do ano são causadas pelo movimento de translação terrestre e inclinação da órbita da Terra; e, um aluno (8\%) respondeu que se devem ao movimento de translação terrestre. No pré-teste sete alunos (58\%) acertaram a questão sobre as estações do ano, enquanto no pós-teste três alunos (25\%) responderam corretamente e sete $(58 \%)$ responderam parcialmente. Embora no pós-teste sete alunos responderam parcialmente, apenas um aluno ainda acreditava que as estações do ano são causadas pela distância entre a Terra e o Sol. A Figura 14 apresenta uma das respostas para esta questão. 
Figura 14 - Uma das respostas para a primeira pergunta do pós-teste

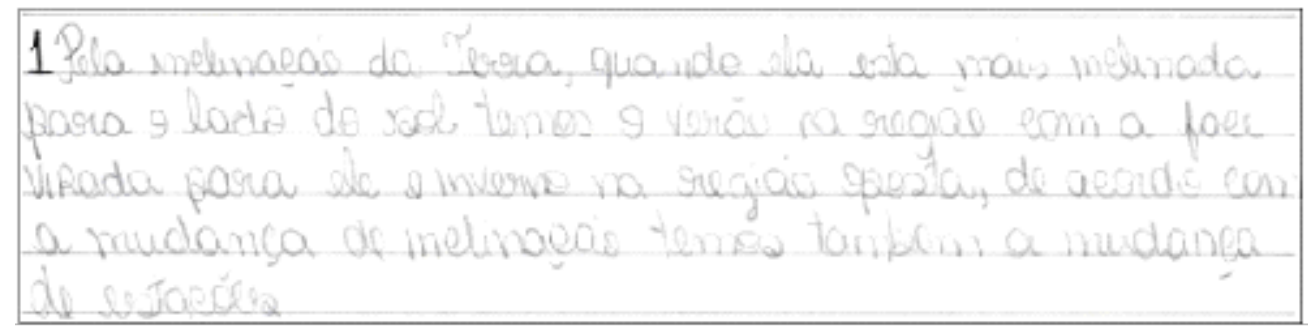

Fonte: extraído do formulário inicial

A resposta apresentada na Figura 14 mostra que o aluno compreendeu parcialmente a ocorrência das estações do ano, pois explicou que elas ocorrem devido à inclinação da Terra em sua órbita, porém não mencionou a translação.

A segunda pergunta analisou o entendimento dos alunos sobre os eclipses. No pré-teste também houve uma pergunta a respeito dos eclipses, porém sem uma figura. Observa-se que o eclipse representado no pós-teste é o eclipse solar, pois um observador situado na Terra pode não visualizar o Sol devido ao alinhamento entre o Sol, a Lua e a Terra, conforme apresentado na Figura 14. Além disso, a Lua vista por um observador na superfície terrestre recebe iluminação solar mínima, mostrando que esta é a fase da Lua Nova. Seis alunos (50\%) responderam corretamente eclipse solar e Lua Nova; três alunos (25\%) afirmaram se tratar de eclipse lunar e Lua Nova; dois alunos (17\%) indicaram que é o eclipse solar e a Lua Cheia; um aluno (8\%) escreveu eclipse lunar e Lua Cheia e um aluno (8\%) respondeu apenas eclipse solar. Observa-se que nove alunos (75\%) acertaram o tipo de eclipse e nove alunos (75\%) acertaram a fase da Lua, porém apenas seis alunos (50\%) conseguiram relacionar o tipo de eclipse e a fase da Lua correspondente.

No pré-teste existiam duas perguntas separadas sobre eclipses e fases da Lua. Na pergunta sobre eclipses nove alunos (75\%) compreenderam as causas do eclipse solar, enquanto na pergunta sobre fases da Lua sete alunos (58\%) conseguiram relacionar a figura apresentada com a fase lunar correspondente. Estes dados mostram que, embora alguns alunos ainda não compreendam corretamente a causa das fases da Lua e dos eclipses, já conseguem relacionar estes dois fenômenos com a posição aparente do Sol, da Terra e da Lua, e não com achismos.

A terceira pergunta analisou a compreensão dos alunos sobre as constelações. Nove alunos (75\%) responderam corretamente que as constelações são conjuntos de estrelas aparentemente próximas. Um aluno (8\%) explicou que as constelações são signos e dois alunos (17\%) não responderam a esta pergunta. A segunda parte da pergunta buscava identificar as constelações que os alunos já conseguiam visualizar no céu. A Figura 15 apresenta a relação entre as respostas e as constelações. 
Figura 15 - Respostas dos alunos sobre as constelações

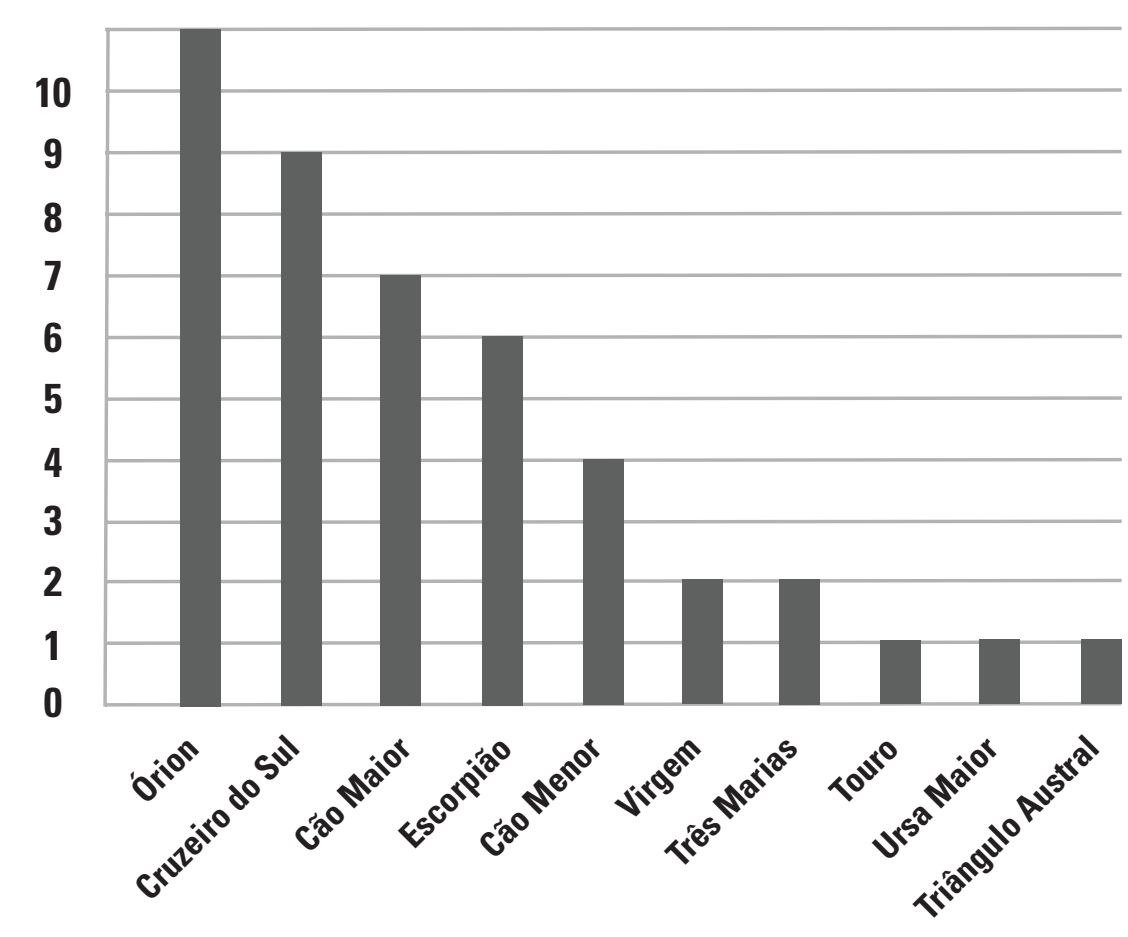

Fonte: extraído do formulário inicial

Ao analisar a Figura 16, observa-se que dois alunos (17\%) não compreenderam que as Três Marias fazem parte da constelação de Órion. Além disso, um aluno (8\%) não analisou o fato de que a Ursa Maior só é vista no Hemisfério Norte. Mesmo com alguns equívocos, observa-se que os alunos já conseguem visualizar várias constelações no céu. Este fato pode ter sido influenciado pelas aulas práticas de observação do céu a olho nu e pelo telescópio, com o auxílio do software Stellarium e do aplicativo SkyMap.

A última questão do pós-teste analisou se os alunos compreenderam os procedimentos para a localização noturna no hemisfério Sul, através da constelação do Cruzeiro do Sul, e no Hemisfério Norte, pela observação da Estrela Polar. Sobre a localização noturna no Hemisfério Sul, sete alunos (58\%) responderam corretamente que é preciso utilizar o Cruzeiro do Sul; quatro (33\%) não souberam responder; um aluno (8\%) explicou que é possível se localizar a noite observando o nascer ou ocaso do Sol. Sobre a localização noturna no Hemisfério Norte, sete alunos (58\%) responderam corretamente que é preciso observar a constelação da Ursa Maior; três alunos (25\%) não souberam responder e dois alunos (17\%) explicaram que é possível se localizar a noite observando o nascer ou ocaso do Sol. Uma das justificativas para os alunos terem respondido sobre a observação do nascer ou ocaso do Sol está na localização diurna por meio dos pontos cardeais que necessitam do entendimento sobre a região do nascer do Sol (Leste) e do ocaso do Sol (Oeste). Os resultados obtidos na aplicação da última pergunta demonstram o entendimento de vários alunos sobre as técnicas de observação do céu. Estas técnicas são importantes para a compreensão do movimento aparente das estrelas. 
Após a aplicação do pós-teste, houve discussões sobre o aprendizado nas aulas, a importância do site e dos estudos para a Olimpíada Brasileira de Astronomia e Astronáutica. Os alunos também destacaram que o uso de recursos tecnológicos facilitou o aprendizado de conceitos que eles ainda não sabiam e que, através destes recursos, tiveram a oportunidade de visualizar fenômenos de maneira simples. Além disso, foram feitas as resoluções do pré-teste e do pós-teste, permitindo aos alunos compreender a evolução destes durante as aulas. A análise dos resultados nos testes e demais atividades permitiu a reflexão sobre melhorias que devem ser feitas em novas edições deste curso. Depois da finalização das aulas, foi solicitado aos alunos o preenchimento de um formulário final com reflexões sobre o curso.

Dentre as perguntas deste formulário, foi questionado aos alunos se faltou alguma coisa no curso, se foi importante a existência de um local na Internet para o acesso aos conteúdos e quais foram as partes positivas e negativas do curso. De maneira geral, os alunos destacaram como partes positivas a aprendizagem de conteúdos que não haviam estudado na escola utilizando-se de aulas práticas, visualização do céu, uso de recursos tecnológicos e do site do curso. Como partes negativas, ou no tocante a fatores faltantes no curso, a maioria dos alunos destacou o pouco tempo de aulas e também a falta de base que eles possuíam para aprender conteúdos mais complexos como aqueles explorados pela Astronáutica. Todos responderam que o site foi importante para a aprendizagem. Diante das respostas dos alunos ao formulário final, observa-se que o curso conseguiu atrair a atenção e o interesse para a aprendizagem em Astronomia e também em Astronáutica. Além de aprender por meio de aulas presenciais, os alunos destacaram o site como recurso para o aprendizado.

\section{Considerações finais}

A Olimpíada Brasileira de Astronomia e Astronáutica foi um importante motivo para a elaboração e aplicação de um curso voltado aos alunos do Ensino Médio interessados em conteúdos relacionados com a Astronomia. Diante dos relatos presentes neste artigo, observa-se que os alunos se interessaram e procuraram aprofundar os conhecimentos adquiridos durante as aulas. Também compreenderam vários dos conteúdos e fenômenos astronômicos, modificando seus entendimentos sobre eles. Foi notado que vários alunos não tiveram a oportunidade de estudar conceitos básicos de Astronomia em anos anteriores, fato que reforça a necessidade de ações voltadas para a divulgação e ensino desta ciência. Além disso, mesmo aqueles que não possuíam interesse nas aulas da escola demonstraram comprometimento com o curso. $O$ ensino de Astronáutica também esteve presente através da resolução de questões da OBA, vídeos e documentários que apresentaram o funcionamento de foguetes, a evolução das viagens espaciais e outras informações. A participação dos alunos na Mostra Brasileira de Foguetes (MOBFOG), foi importante para entender na prática as teorias estudadas. 
A OBA e a MOBFOG se tornaram essenciais para a realização do curso, por incentivar os alunos no estudo para as olimpíadas e, consequentemente, aprender e se interessar por conteúdos que normalmente não são ensinados nas escolas. Por isto, é interessante que os professores apresentem as olimpíadas do conhecimento, não como disputas, mas sim como novos aprendizados.

A educação não formal desempenha um importante papel como complemento à educação formal por permitir que pessoas interessadas no aprendizado de determinados conteúdos tenham a oportunidade de estudar além do currículo oficial dos estabelecimentos de ensino. Infelizmente, o curso demonstrou que a aprendizagem em Astronomia e Astronáutica de alguns alunos participantes era incipiente e que estes iriam completar a educação básica sem aprender conhecimentos essenciais destas ciências que poderiam auxiliá-los em uma maior compreensão do mundo em que vivem.

O site do curso permitiu aos alunos a oportunidade de continuar os estudos através de um ambiente virtual com vários conteúdos, curiosidades e informações para os interessados em complementar seus estudos e avançar no conhecimento sobre a Astronomia, Astronáutica e a Ciência em geral. Além disso, o uso de recursos tecnológicos esteve presente no curso através de formulários online, do site do curso, software Stellarium, aplicativo SkyMap, de vídeos, do uso do WhatsApp e de computadores na sala de informática. Mesmo com o uso destes e demais recursos, foram realizadas atividades práticas e a observação do céu a olho nu e pelo telescópio, além de discussões e resoluções de questões da OBA. Esta relação entre a tecnologia e as atividades tradicionais de ensino, principalmente por meio da valorização da observação do céu, são importantes por demostrar que o uso da tecnologia também depende de demais atividades para a obtenção de resultados satisfatórios.

\section{Referências}

ANGOTTI, J. Solução alternativa para a formação de professores de ciências: um projeto educacional desenvolvido na Guine-Bissau. 1982. Dissertação (Mestrado em Educação e Ensino em Física) Universidade de São Paulo, São Paulo, 1982.

BARAI, A.; NETO, J.; GARRIDO, D.; ITYANAGUI, G.; NAVI, M. Astronomia nos anos iniciais do Ensino Fundamental: uma parceria entre universidade e escola. Caderno Brasileiro de Ensino de Física, v. 33 , n. 3, 2016, p. 1009-1025.

$\mathrm{BISCH}, \mathrm{S}$. Astronomia no Ensino fundamental: natureza e conteúdo do conhecimento de estudantes e professores. 1998. Tese (Doutorado em Educação em Astronomia) - Universidade de São Paulo, São Paulo, 1998.

BRETONES, P.; COMPIANI, M. A observação do céu como ponto de partida e eixo central em um curso de formação continuada de professores. Ensaio Pesquisa em Educação em Ciências, v. 12, n. 2, 2010, p. 173-188. 
CAMINO, N. Ideias anteriores e mudança conceitual em astronomia: Um estudo com professores primários sobre o dia e a noite, as estações e as fases da lua. Ensino de ciências: revista de investigação e experiências didáticas, v. 13, n. 1, 1995, p. 81-96.

CANALLE, J.; ROCHA, J.; SOUZA, C.; ORTIZ, R.; AGUILERA, N.; PADILHA, M.; PESSOA FILHO, J.; RODRIGUES, I. VIII Olimpíada Brasileira de Astronomia e Astronáutica. Bulletin of the Astronomical Society of Brazil, v. 26, n. 2, 2007, p. 31-68.

CANIATO, R. Um projeto brasileiro para o ensino de física. 1973. Tese (Doutorado em Educação em Astronomia) - Universidade Estadual de São Paulo Júlio Mesquita, Rio Claro, 1974.DARROZ, L. M.; SANTOS, F. M. T. Astronomia: uma proposta para promover a aprendizagem significativa de conceitos básicos de Astronomia na formação de professores em nível médio. Caderno Brasileiro de Ensino de Física, v. 30, n. 1, 2013, p. 104-130.

DELIZOICOV, D. Concepção problematizadora do ensino de ciências na educação formal: relato e análise de uma prática educacional na Guiné Bissau. 1982. 1982. Tese ( Doutorado em Estudo e Ensino de Física) - Universidade de São Paulo, São Paulo, 1982.

DELIZOICOV.Conhecimento, tensões e transições. 1991. Tese (Doutorado em Educação) - Universidade Federal de Santa Catarina, Florianópolis, 1991.

DELIZOICOV, D.; ANGOTTI, J. A.; PERNAMBUCO, M. M. C. A. Ensino de Ciências: fundamentos e métodos. São Paulo: Cortez, 2002.

FELICETTI, S. A.; ISABEL, I. C. M. L.; OHSE, M. L. Aprendizagem de conceitos de astronomia no ensino fundamental: uma oficina didática em preparação para a OBA. Góndola, Enseñanza y Aprendizaje de las Ciencias, v. 12, n. 2, 2017, p. 32-49.

FERREIRA, O. CTS-ASTRO: Astronomia no enfoque da Ciência, Tecnologia e Sociedade e Estudo de Caso em Educação a Distância. 2014. Dissertação (Mestrado em Educação em Astronomia) - Universidade Cruzeiro do Sul, São Paulo, 2014.

FREIRE, P. Extensão ou comunicação? 6. ed. Rio de Janeiro: Editora Paz e Terra SA, 1975.

GASPAR, A. A educação formal e a educação informal em ciências. In: MASSARANI, L.; MOREIRA, I.; BRITO, F. (Orgs.). Ciência e Público. Rio de Janeiro: Casa da Ciência, 2002.

GOHN, M. Educação não-formal, participação da sociedade civil e estruturas colegiadas nas escolas. Ensaio: avaliação e políticas públicas em educação, v. 14, n. 50, 2006, p. 27-38.

IACHEL, G. O conhecimento prévio de alunos do ensino médio sobre as estrelas. Revista LatinoAmericana de Educação em Astronomia, n. 12, 2011, p. 7-29.

KENSKI, V. Educação e tecnologias: o novo ritmo da informação. Campinas: Papirus Editora, 2007.

LANGHI, R.; NARDI, R. Educação em Astronomia: repensando a formação de professores. São Paulo: Escritoras editoras, 2012.

LANGHI. Ensino de Astronomia: Erros conceituais mais comuns presente em livros didáticos de ciência. Caderno Brasileiro de Ensino de Física, v. 24, n. 1, 2007, p. 87-111. 
LANGHI. Ensino da astronomia no Brasil: educação formal, informal, não formal e divulgação científica. Revista Brasileira de Ensino de Física, v. 31, n. 4, 2009, p. 4402-4412.

LEITE, C.; HOSOUME, Y. Os professores de ciêncixas e suas formas de pensar a astronomia. Revista LatinoAmericana de Educação em Astronomia, n. 4, 2007, p. 47-68.

LONGHINI, M. D. Educação em astronomia: experiências e contribuições para a prática pedagógica. Campinas: Átomo, 2010.

MARANDINO, M. (Org.). Educação em museus: a mediação em foco. São Paulo: Geenf/FEUSP, 2008. Disponível em: https://bit.ly/2L8M4oM. Acesso em: 31 dez. 2020.

MARQUES, J. Educação não-formal e divulgação de astronomia no Brasil: atores e dinâmica da área na perspectiva da Complexidade. Tese (Doutorado em Educação) - Universidade Federal de São Carlos, São Carlos, 2017.

RAVOTTO, P.; BELLINI, R. Quali competenze digitali per insegnare al tempo del web 2.0? Associazone Italiana Per L'Informatica e il Calcolo Automatico, [s. d.]. Disponível em: https://bit.ly/3ujPsPE. Acesso em: 10 nov. 2020.

RODRIGUES, M. A. Os planetas do sistema solar em livros didáticos de ciências da quinta série do ensino fundamental. Experiências em Ensino de Ciências, v. 2, n. 2, 2007, p. 1-10.

SÁ, K. A olimpiada brasileira de física em Goiás enquanto ferramenta para a alfabetização científica: tradução de uma educação não formal. 2009. Dissertação (Mestrado em Linguística, Letras e Artes) Universidade Federal de Goiás, Goiânia, 2009.

SIEMSEN, G.; LORENZETTI, L. A Astronomia ao longo das três versões da Base Nacional Comum Curricular para o Ensino Fundamental. In: ENCONTRO NACIONAL DE PESQUISA EM EDUCAÇÃO EM CIÊNCIAS, 12. Anais... Natal, 2019.

SOBREIRA, P. H. A. Astronomia no ensino de Geografia: análise crítica nos livros didáticos de Geografia. 2002. Tese (Doutorado em Educação em Astronomia) - Universidade de São Paulo, São Paulo, 2002.

TIGNANELLI, H. Sobre o ensino da astronomia no ensino fundamental. In:WEISSMANN, H. (Org.). Didática das ciências naturais: contribuições e reflexões. Porto Alegre: Artmed, 1998. 